This project has received funding from the European Union's Horizon 2020 research and innovation programme under the Marie Sklodowska-Curie grant agreement No 704459.

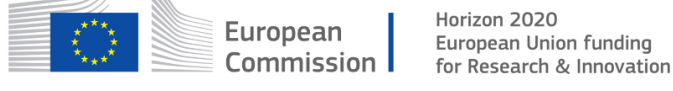

\title{
Evolution of microphase separation with variations of segments of sequence- controlled multiblock copolymers
}

Junliang Zhang, ${ }^{1}$ Robert Deubler, ${ }^{2,3}$ Matthias Hartlieb, ${ }^{1}$ Liam Martin, ${ }^{1}$ Joji Tanaka, ${ }^{1}$ Elena Patyukova, ${ }^{4}$ Paul D. Topham, ${ }^{4}$ Felix H. Schacher, ${ }^{2,3}$ Sébastien Perrier ${ }^{1,5,6 *}$

1 Department of Chemistry, The University of Warwick, Coventry CV4 7AL, U.K.;

2 Institute of Organic Chemistry and Macromolecular Chemistry, Friedrich-Schiller-University Jena, Lessingstraße 8, D-07743 Jena, Germany

3 Jena Center for Soft Matter, Friedrich-Schiller-University Jena, Philosophenweg 7, D-07743 Jena, Germany

4 Aston Institute of Materials Research, Aston University, Aston Triangle, Birmingham, B4 7ET, U.K.

5 Warwick Medical School, The University of Warwick, Coventry CV4 7AL, U.K.;

6 Faculty of Pharmacy and Pharmaceutical Sciences, Monash University, VIC 3052, Australia

* Correspondence to: s.perrier@warwick.ac.ukMultiblock copolymers (MBCPs) are emerging class of materials that are becoming more accessible in recent years. However, to date there is still a lack of fundamental understanding of their physical properties. In particular, the glass transition temperature $\left(T_{g}\right)$ which is known to be affected by the phase separation has not been well characterised experimentally. To this end, we report the first experimental study on the evolution of the $T_{\mathrm{g}} \mathrm{s}$ and the corresponding phase separation of linear MBCPs with increasing number of blocks whilst keeping the overall degree of polymerisation (DP) constant (DP $=200$ ). Ethylene glycol methyl ether acrylate (EGMEA) and tert-butyl acrylate ( $t \mathrm{BA})$ were chosen as monomers for reversible addition-fragmentation chain transfer polymerization to synthesise MBCPs. We found the $T_{\mathrm{g}} \mathrm{s}$ (as measured by Differential Scanning Calorimetry) of EGMEA and tBA segments within the MCBPs to converge with increasing number of blocks and decreasing block length, correlating with the loss of the heterogeneity as observed from Small Angel X-ray Spectroscopy (SAXS) analysis. The $T_{\mathrm{g}} \mathrm{S}$ of the multiblock copolymers were also compared to the $T_{\mathrm{g}} \mathrm{S}$ of the polymer blends of the corresponding homopolymers, and we found that $T_{\mathrm{g}} \mathrm{s}$ of the polymer blends were similar to those of the respective homopolymers, as expected. SAXS experiments further demonstrated microphase separation of multiblock copolymers. 
This work demonstrates the enormous potential of multiblock architectures to tune the physical properties of synthetic polymers, by changing their glass transition temperature and their morphologies obtained from microphase separation, with domain sizes reaching under $10 \mathrm{~nm}$. 


\section{Introduction:}

Sequence regulated synthetic macromolecules, called multiblock copolymers (MBCPs), form an interesting class of materials, where the properties and functionality can be controlled on demand. ${ }^{1,2}$ Multiblock copolymers have opened up a new perspective for building functional polymer architectures with tailored morphologies. ${ }^{3-5}$ Advances in the synthesis of multiblock copolymers have offered a novel platform to manipulate the microdomain structures (e.g. spherical, cylindrical or lamellar domains) of synthetic materials in terms of block length, polymer architecture, or choice of monomers. ${ }^{1,6-11}$ Microphase separated block copolymers have appealing properties (for applications such as nanoscale lithography, ionic conductivity, or energy storage) that are influenced significantly by their microdomain structures. ${ }^{12-20}$ Tuning the molecular composition of the block copolymer can influence both type and domain size of the respective bulk morphologies upon self-assembly in the solid state and this might allow generating materials with designed properties for nanotechnology applications..$^{21-24}$

Phase behavior in $(A B)_{n}$ multiblock copolymers has been a subject of ongoing theoretical ${ }^{25-32}$ and experimental ${ }^{30,}$, 33-37 research over recent twenty years. It was shown that $(A B)_{n}$ linear multiblock copolymer phase behavior qualitatively is similar to that of $A B$ diblock copolymers ${ }^{25,26}$ and is governed by the composition $f$ of the block copolymer (where $f_{\mathrm{A}}$ is the volume fraction of the A block), and the product $\chi \mathrm{N}_{\text {eff }}$ (where $\chi$ is the Flory-Huggins parameter describing excluded volume interactions between $A$ and $B$ blocks, and $N_{\text {eff }}$ is the effective number of monomer units in a diblock copolymer obtained by dissecting the multiblock copolymer under study into constituent diblocks). Thus, depending on the composition of the multiblock copolymer and the degree of segregation, ordered lamellar, cylindrical, bcc spherical, hcp spherical, gyroid and Fddd phases are expected to be observed. These theoretical predictions are in perfect agreement with experimental observations. ${ }^{30,33-37}$

The largest difference in terms of phase behaviour of multiblock copolymers with respect to diblock copolymer systems is expected when operating close to the order-disorder transition (ODT). ${ }^{30,32}$ It was shown that ordering in multiblock copolymers occurs at lower values of $\chi \mathrm{N}_{\text {eff }}$ compared to diblock copolymers with the same value of $\chi \mathrm{N}$. This is explained by the lower value of both translational and conformational entropy of a multiblock copolymer system compared to the equivalent diblock copolymer system. Interestingly, it was shown by Wu et al. that taking into account fluctuations shifts ODT in $(A B)_{n}$ multiblock copolymers upwards relative to the mean-field prediction by the value independent of number of blocks in a multiblock. ${ }^{30}$

However, understanding phase behaviour is just the first step on the way fully understanding about multiblock copolymer properties relevant for applications. The material properties of synthetic 
polymers are to a large extent dependent on the thermal response, such as glass transition or crystallization behaviour. ${ }^{38}$

The glass transition temperature $\left(T_{\mathrm{g}}\right)$ plays a significant role in the applications of synthetic materials and the $T_{\mathrm{g}}$ values are useful for a variety of purposes, ${ }^{39-42} \mathrm{e.g}$. intelligent medical devices, ${ }^{43}$ implants for minimally invasive surgery, ${ }^{44,45}$ producing 'breathable clothing', ${ }^{46}$ or fabricating devices with high ionic conductivity using soft (low $T_{\mathrm{g}}$ ) polymers featuring rapid segmental motion and low rigidity. ${ }^{47}$

A large body of work has focused on studying the correlation between the structure of block copolymers and the glass transition temperature in order to further investigate the microdomain morphologies and physical properties. ${ }^{48-53}$ Recently, Zuckermann et al. synthesized a series of sequence-defined peptoid diblock copolymers by solid-phase synthesis and investigated the nanoscale phase separation of these materials. ${ }^{14}$ With this approach it was possible to tune the intraand intermolecular interactions of block copolymers, proving the system to be useful for fundamental studies of block copolymer self-assembly. More recently, Gao et al. reported the investigation of the effect of monomer sequence on the $T_{\mathrm{g}}$ of segmented hyperbranched copolymers, ${ }^{54}$ proving that segmentation significantly affects the glass transition.

Dependence of the number and length of blocks on the glass transition of linear multiblock copolymers was studied in works of Spontak et $a .^{37}$ and Lee et $a l .{ }^{34}$ In the former, symmetrical poly(styrene-bisoprene $)_{n}(1 \leq n \leq 4)$ multiblock copolymers were studied. They considered two multiblock copolymer series: one with constant block length and the second with constant overall multiblock chain length. All samples showed long range lamellar order where the domain size decreased as $n^{0.8}$ for the series with constant chain molecular mass. For the first series, domain size also decreased with increase in the number of blocks but this dependence was not as strong. Multiblock copolymer samples showed interesting thermal behaviour. The authors found that the lower (isoprenic) glass transition was insensitive to the number of blocks, however the higher (styrenic) glass transition temperature showed a decrease on increase in $\mathrm{n}$. The effect was more pronounced for the second series in their study.

Lee et $a l .{ }^{34}$ studied the phase behavior of poly(styrene-b-butadiene) $)_{\mathrm{n}}$ multiblock copolymers with alternating $(n=7,8,11,15)$ and random $(n=16,21,24,25)$ sequence and volume fraction of PS block in the range $69 \%-85 \%$ PS. The length of block was fixed and the number of blocks was varied. They found lamellar for alternating tetrablock copolymer. All other samples were disordered, but inhomogeneous. They found a slight decrease in the higher glass transition temperatures and an increase in the lower $T_{\mathrm{g}}$ compared to the glass transition temperatures of the corresponding 
homopolymers. These small differences increased with decreasing block length. Shifts in $T_{\mathrm{g}}$ were attributed to microphase mixing of PS and PB blocks.

In this work we synthesize and study microphase separation and thermal properties of symmetric poly(ethylene glycol methyl ether acrylate-b-tert-butyl acrylate) [(EGMEA-tBA) ${ }_{n}$ multiblock copolymers with overall fixed degree of polymerisation but different number of blocks. In contrast to study of Spontak, et al., ${ }^{37}$ we consider short blocks and probe the region near order-disorder transition. We found the $T_{\mathrm{g}} \mathrm{s}$ of the segments to converge with increasing number of blocks and decreasing block length, correlating with the loss of the heterogeneity as observed from Small Angel X-ray Spectroscopy (SAXS) analysis. Our approach highlights the potential of MBCP for tuning the physical properties of synthetic polymers. 


\section{Results and Discussions:}

Very recently, our group developed a simple and scalable approach to synthesize well-defined sequence controlled multiblock copolymers with quantitative monomer conversions using a wide range of monomers in a one-pot approach, which showed enormous potential to generate synthetic polymers with complex architectures. ${ }^{1,8}$ Herein, we applied this method to systematically explore the effect of the segmentation on the $T_{\mathrm{g}}$ dependence and nanoscale phase separation in linear multiblock copolymers.

A series of sequence controlled multiblock copolymers (diblock, tetrablock, hexablock, octablock and icosablock) based on two different monomers, ethylene glycol methyl ether acrylate (EGMEA, A) and tert-butyl acrylate $(t \mathrm{BA}, \mathrm{B})$, as well as their corresponding homopolymers and statistical copolymers were synthesized by RAFT polymerization. The block copolymers were synthesized with alternating order of the two monomers (e.g. ABAB for a tetrablock). Importantly, the total targeted degree of polymerization (DP) of each copolymer was set at 200 with a monomer ratio of 1:1, in order to keep the overall chemical composition of each multiblock copolymer constant while the degree of segmentation was varied (Scheme 1a, Table 1). 
(a)

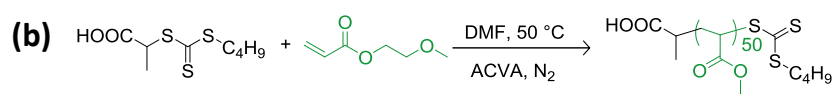

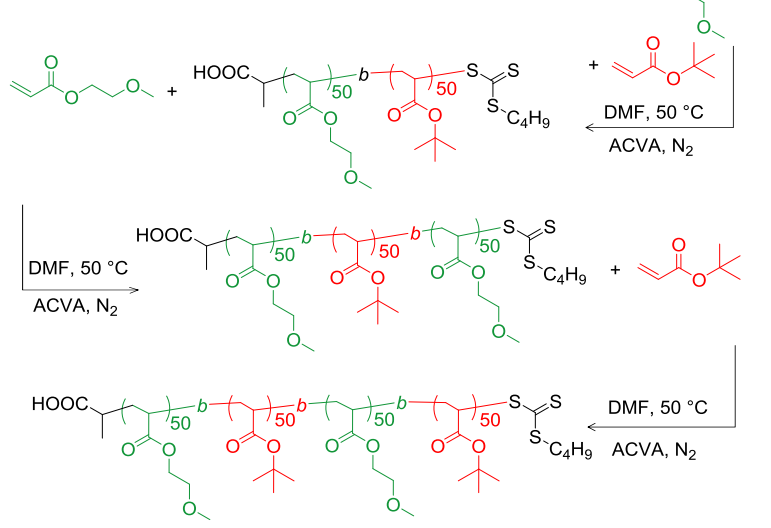

Scheme 1. a) Schematic Representation of Multiblock Copolymers Investigated in this Study. b) Synthesis of the Tetrablock Copolymer of $A_{50} B_{50} A_{50} B_{50}$ by RAFT Polymerization (where $A$ and $B$ represent EGMEA and $t B A$, respectively).

All MBCPs were synthesized by RAFT polymerization in a one pot approach using sequential monomer addition for each block. In order to avoid side reactions of the acrylate monomers during the polymerization, all polymerizations were carried out in DMF at a relatively low temperature $\left(50^{\circ} \mathrm{C}\right)$ using 2-((butylthio)-carbonothioyl) thio propanoic acid (referred to as (propanoic acid)yl butyl trithiocarbonate (PABTC) in this paper) as chain transfer agent (CTA) and 4, 4'-azobis(4-cyanovaleric acid) (ACVA) as initiator. Scheme $\mathbf{1 b}$ illustrates the synthesis of the tetrablock copolymer of $\mathbf{A}_{50} \mathbf{B}_{50} \mathbf{A}_{50} \mathbf{B}_{50}$. The detailed synthetic procedures of these multiblock copolymers can be found in the Electronic Supporting Information (ESI, Tables S1-S6). MBCPs were analysed by ${ }^{1} \mathrm{H}$ NMR and SEC to determine conversion after each step and confirm the successful chain extension.

${ }^{1} \mathrm{H}$ NMR spectra of MBCPs showed near quantitative monomer conversion ( $\geq 96 \%$, see SI Figure S1S5, see Figure S1 for a detailed structural assignment for the ${ }^{1} \mathrm{H}$ NMR spectrum of the diblock 
copolymer $\mathbf{A}_{100} \mathbf{B}_{100}$ as an example) for each block extension. The molecular weight distributions were characterized by Size Exclusion Chromatography (SEC, see SI Figure S6-S10), revealing monomodal distributions with a clear shift to higher molecular weights after each monomer addition. However, some low-molecular-weight tailing was observed after each chain extension, which can be ascribed to the accumulation of initiator-derived dead chains, or possible interactions of the multiblock copolymer with the SEC column. ${ }^{1,8,9}$ These findings are more prevalent for the icosablock (20 blocks) system; as a higher number of blocks was targeted, a higher initial initiator concentration was required to reach full monomer conversion after each step. ${ }^{9}$ The increased propagating radical concentration, however, also increases the number of termination events (initiator derived chains). ${ }^{55}$ However, assuming that the segment lengths of the individual blocks are similar, the presence of dead chains with different number of segments surely affects the overall dispersity, but not necessarily the (vide infra) self-assembly in the bulk. The high molecular weight shoulder detected by SEC is likely associated to the copolymerization of macromonomer formed by the propagating radical undergoing backbiting $\beta$-scission, which occurs during the radical polymerization of acrylates. ${ }^{9,56-58}$

Table 1. Characterization of the Multiblock Copolymers by ${ }^{1} \mathrm{H}$ NMR, $\mathrm{CHCl}_{3}-\mathrm{SEC}$ and DSC.

\begin{tabular}{|c|c|c|c|c|c|c|}
\hline & Sample & $\begin{array}{c}M_{\mathrm{n}, \mathrm{th}^{\mathrm{c}}} \\
\mathrm{g} \mathrm{mol}^{-1}\end{array}$ & $\begin{array}{l}M_{\mathrm{n}, \mathrm{SEC}}{ }^{\mathrm{d}} \\
\mathrm{g} \mathrm{mol}^{-1}\end{array}$ & $\bigoplus^{\mathrm{d}}$ & $\begin{array}{c}\mathrm{P}(\mathrm{A}) \mathrm{g}_{\mathrm{g}}^{\mathrm{e}} \\
{ }^{\circ} \mathrm{C}\end{array}$ & $\begin{array}{c}\mathrm{P}(\mathrm{B}) T_{\mathrm{g}}^{\mathrm{e}} \\
{ }^{\circ} \mathrm{C}\end{array}$ \\
\hline & $\mathrm{A}_{200^{\mathrm{a}}}$ & 26,300 & 24,700 & 1.11 & $-32.3 \pm 0.2$ & - \\
\hline & $\mathrm{B}_{200^{\mathrm{b}}}$ & 25,900 & 24,500 & 1.09 & - & $47.9 \pm 0.3$ \\
\hline $\mathrm{BCP}^{\mathrm{di}}$ & $\mathrm{A}_{100} \mathrm{~B}_{100}$ & 26,100 & 24,800 & 1.17 & $-30.9 \pm 0.3$ & $39.1 \pm 0.2$ \\
\hline $\mathrm{BCP}$ tetra & $\mathrm{A}_{50} \mathrm{~B}_{50} \mathrm{~A}_{50} \mathrm{~B}_{50}$ & 26,100 & 22,700 & 1.26 & $-28.1 \pm 0.1$ & $23.3 \pm 0.2$ \\
\hline BCPhexa & $\mathrm{A}_{33} \mathrm{~B}_{33} \mathrm{~A}_{33} \mathrm{~B}_{33} \mathrm{~A}_{33} \mathrm{~B}_{33}$ & 25,800 & 21,200 & 1.37 & $-26.6 \pm 0.6$ & $10.1 \pm 0.4$ \\
\hline $\mathrm{BCP}^{\text {octa }}$ & $\mathrm{A}_{25} \mathrm{~B}_{25} \mathrm{~A}_{25} \mathrm{~B}_{25} \mathrm{~A}_{25} \mathrm{~B}_{25} \mathrm{~A}_{25} \mathrm{~B}_{25}$ & 26,100 & 23,300 & 1.34 & $-22.6 \pm 1.0$ & $3.1 \pm 0.6$ \\
\hline BCPicosa & $\left(\mathrm{A}_{10} \mathrm{~B}_{10} \mathrm{~A}_{10} \mathrm{~B}_{10} \mathrm{~A}_{10} \mathrm{~B}_{10} \mathrm{~A}_{10} \mathrm{~B}_{10} \mathrm{~A}_{10} \mathrm{~B}_{10}\right)_{2}$ & 26,100 & 21,200 & 1.67 & $-9.9 \pm 0.4$ & $-9.9 \pm 0.4$ \\
\hline $\mathrm{CP}^{\mathrm{ran}}$ & $\mathrm{A}_{100}-r a n-\mathrm{B}_{100}$ & 26,100 & 25,300 & 1.10 & & \\
\hline
\end{tabular}

\footnotetext{
${ }^{\mathrm{a}} \mathrm{A}$ represents the monomer EGMEA

${ }^{b} B$ represents the monomer tBA

${ }^{c} M_{\mathrm{n}, \mathrm{th}}=\left([\mathrm{M}]_{0} \times \mathrm{p} \times M_{\mathrm{M}}\right) /[\mathrm{CTA}]_{0}+M_{\mathrm{CTA}}$, where $\mathrm{p}$ is the monomer conversion

${ }^{\mathrm{d}}$ Determined by SEC in $\mathrm{CHCl}_{3}$ with PMMA used as molecular weight standards

e Data represent mean \pm SD $(n=3)$.
} 


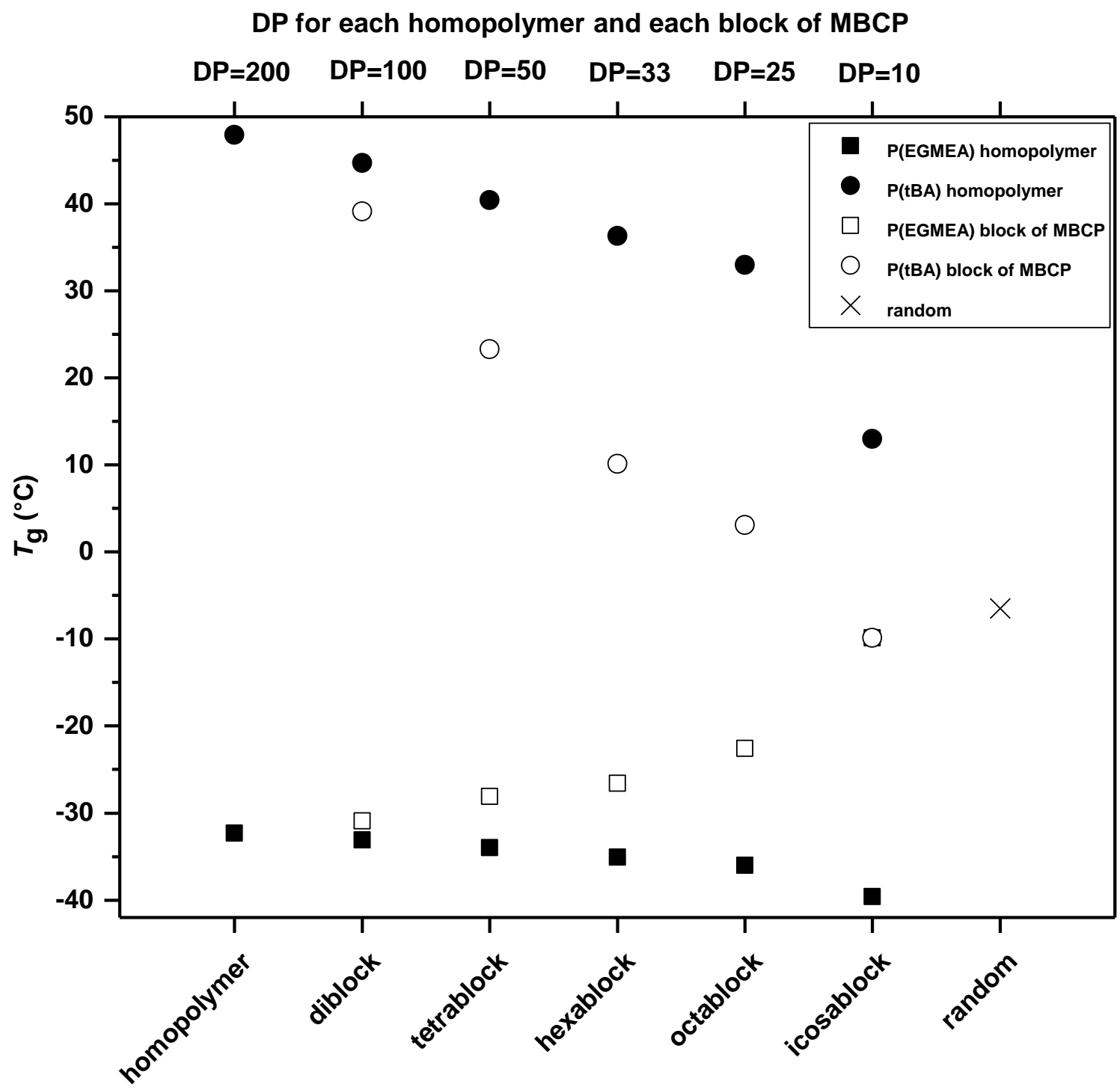

Figure 1. Comparison of $T_{\mathrm{g}}$ values of multiblock copolymers (total DP $=200$ ), homopolymers EGMEA and tBA (DP $=200,100,50,33,25,10$, respectively) and statistical copolymer of EGMEA and tBA (DP $=200$ ). Data represent mean values only (error bars within point size, see Tables 1 and S8 for SD).

The microphase separation of MBCPs and the influence of the segmentation on the $T_{\mathrm{g}}$ were investigated using DSC measurements. The results are shown in Table 1, Figure 1 and DSC curves are depicted in the supporting information (Figures S11-S15). Based on all of the DSC traces of the MBCPs, melting peaks and crystallization exotherms were not observed, showing that all of these MBCPs are noncrystalline. ${ }^{14,18,59}$ As a control, a statistical copolymer with a DP of 200 (DP 100 for each monomer) was synthesized as well. Based on the polymerization kinetic study (Figures S16-S18), the two monomers $\mathbf{A}$ and $\mathbf{B}$ had the same reactivity, which indicates a random distribution along the copolymer chain. The DSC thermogram of random copolymer (CPran) showed one single $T_{\mathrm{g}}$ value of $6.5^{\circ} \mathrm{C}$ (Table 1, Figure S19) which means there was no microphase separation occurring as expected 
for a random copolymer. On the other hand, the diblock copolymer $\mathbf{B C P}{ }^{d i}\left(\mathbf{A}_{100} \mathbf{B}_{100}\right)$ showed two distinct $T_{\mathrm{g}}$ at $-30.9{ }^{\circ} \mathrm{C}$ and $39.1{ }^{\circ} \mathrm{C}$ (Table 1, Figure S11) indicative of phase separation. The tetrablock copolymer $\mathbf{B C P}{ }^{\text {tetra }}\left(\mathbf{A}_{50} \mathbf{B}_{50} \mathbf{A}_{50} \mathbf{B}_{50}\right)$ was synthesized with a decreased DP of each block (from 100 to 50 ) and an increased segmentation number (from 2 to 4). The DSC thermogram of the tetrablock copolymer BCPtetra also displayed two $T_{\mathrm{g} S}$ of $-28.1{ }^{\circ} \mathrm{C}$ and $23.3{ }^{\circ} \mathrm{C}$ (Table 1, Figure S12), again demonstrating the occurrence of phase separation. The hexablock, $\mathbf{B C} \boldsymbol{P}^{\text {hexa }}\left(\mathbf{A}_{33} \mathbf{B}_{33} \mathbf{A}_{33} \mathbf{B}_{33} \mathbf{A}_{33} \mathbf{B}_{33}\right)$, with a DP of 33 for each block and segmentation number of 6 still shows two $T_{\mathrm{g}}$ values, $-26.6^{\circ} \mathrm{C}$ and 10.1 ${ }^{\circ} \mathrm{C}$ (Table 1, Figure S13). With a further decreased DP of 25 for each block and a more segmented polymer chain, the 8 blocks containing octablock copolymer (BCPocta) still exhibits two $T_{g}$ values, -22.6 ${ }^{\circ} \mathrm{C}$ and $3.1{ }^{\circ} \mathrm{C}$ (Table 1, Figure S14). It is however noteworthy that these latter $T_{\mathrm{g}}$ values were not as clearly observable as for the other aforementioned MBCPs (DSC thermograms shown in Figure S14). Overall it is apparent that the $T_{\mathrm{g}}$ values of the MBCPs shift towards that of the statistical copolymer with increasing segmentation. In order to investigate the effect of segmentation on MBCP microphase separation further, an icosablock copolymer (BCPisoca, DP 10 for each block) was synthesised and analysed. The DSC analysis of BCP isoca demonstrated only one $T_{\mathrm{g}}$ value of $-9.9^{\circ} \mathrm{C}$ (Table 1, Figure S15) which indicates the absence of phase separation. These results show that these multiblock copolymers up to octamer sample have two glass transition temperatures which shows that they are microscopically inhomogeneous.

In addition, homopolymers of each monomer with a DP equal to each block of the multiblock copolymers were synthesized [Tables S7 and S8, ${ }^{1} \mathrm{H}$ NMR spectra (Figures S20-S26), and SEC traces (Figures S27 and S28)] and subsequently analysed by DSC. As expected, the $T_{\mathrm{g}}$ values of the homopolymers decreased with decreasing molecular weight (Figure 1). As the DP decreased from 200 to 10: $\mathbf{A}_{\mathbf{2 0 0}}$ was shown to have a $T_{\mathrm{g}}$ of $-32.3^{\circ} \mathrm{C}$, while the $T_{\mathrm{g}}$ values of $\mathbf{A}_{100}, \mathbf{A}_{50}, \mathbf{A}_{\mathbf{3 3}}, \mathbf{A}_{25}$ and $\mathbf{A}_{10}$ were $-33.1{ }^{\circ} \mathrm{C},-34.0{ }^{\circ} \mathrm{C},-35.1{ }^{\circ} \mathrm{C},-36.0^{\circ} \mathrm{C}$ and $-39.6{ }^{\circ} \mathrm{C}$, respectively (Table S8, figures S29-S34). The $T_{\mathrm{g}}$ values of homopolymers of $\mathrm{B}$ also decreased with decreasing DP. The $T_{\mathrm{g}} \mathrm{s}$ decreased from $47.8^{\circ} \mathrm{C}$ for $\mathbf{B}_{200}$ to $44.7{ }^{\circ} \mathrm{C}, 40.4{ }^{\circ} \mathrm{C}, 36.3{ }^{\circ} \mathrm{C}, 33^{\circ} \mathrm{C}$ and $13{ }^{\circ} \mathrm{C}$ for $\mathbf{B}_{100}, \mathbf{B}_{50}, \mathbf{B}_{33}, \mathbf{B}_{25}$ and $\mathbf{B}_{10}$, respectively (Table S8, Figures S35-S40). Compared to the homopolymers of $\mathbf{A}$, the difference is more pronounced. This is attributed to larger flexibility of homopolymer $\mathbf{A}$, which means that it is difficult to change the $T_{\mathrm{g}}$ dramatically. These results are corroborated by well-known theory, based on the Fox-Flory equation (Equation 1). ${ }^{60,61}$

$$
T_{g}=T_{g, \infty}-K / M_{n} \quad \text { (Equation 1) }
$$

where

$K=2 \frac{\rho N_{A} \theta}{\alpha}$ (Equation 2) 
where $\rho$ is density, $N_{A}$ is Avogadro number, $\theta$ is an average free volume content per chain, $\alpha$ is the thermal expansion coefficient, $T_{\mathrm{g}, \infty}$ is the $T_{\mathrm{g}}$ for the (hypothetical) polymer with an infinite molecular weight and $K$ is an empirical parameter for a specific polymer species. Decreasing molecular weight consequently increases the chain-end concentration. The end groups, however, exhibit greater free volume than units within the chain and possess deficient intermolecular constraints, which will lead to higher segmental mobility and cause a lower $T_{\mathrm{g}} \cdot{ }^{62-67}$ Fitting of our experimental data with Equation 1 gives approximations of $T_{\mathrm{g}(\mathrm{A}), \infty}=-32{ }^{\circ} \mathrm{C}, K_{(\mathrm{A})}=1.3 \times 10^{4} \mathrm{~K}$ and $T_{\mathrm{g}(\mathrm{B}), \infty}=50{ }^{\circ} \mathrm{C}, K_{(B)}=5.5 \times 10^{4} \mathrm{~K}$ (see Figures S41 and S42 in the ESI).

As shown in Figure 1, the comparison between the multiblock copolymers and the homopolymers is particularly striking. The $T_{\mathrm{g}}$ of the $\mathbf{B}$ block dropped significantly from $39.4^{\circ} \mathrm{C}$ for $\mathbf{B}_{100}$ in $\mathbf{B C P}$ di to $-9.9{ }^{\circ} \mathrm{C}$ for $\mathbf{B}_{10}$ in $\mathbf{B C P} \mathbf{P}^{\text {isoca }}$ while it only decreased from $44.7^{\circ} \mathrm{C}$ for homopolymer $\mathbf{B}_{100}$ to $13^{\circ} \mathrm{C}$ for homopolymer $\mathbf{B}_{10}$. Interestingly, an opposing trend was observed for the $T_{\mathrm{g}}$ values of the $\mathbf{A}$ block, which increased for the MBCPs yet decreased for the homopolymers with decreasing DP (Figure 1 ). The $T_{\mathrm{g}}$ of the $\mathbf{A}_{100}$ block in the diblock copolymer $\mathbf{B C P}{ }^{\text {di }}$ was $-30.9{ }^{\circ} \mathrm{C}$ and increased to $-9.9{ }^{\circ} \mathrm{C}$ for $\mathbf{A}_{10}$ block in the icosablock copolymer BCPicosa, whereas it decreased from $-33.1{ }^{\circ} \mathrm{C}$ for homopolymer $\mathbf{A}_{100}$ to $-39.6{ }^{\circ} \mathrm{C}$ for homopolymer $\mathbf{A}_{10}$. As the number of blocks in multiblock copolymer increases and their length correspondingly goes down, degree of segregation in the system also decreases. Boundaries between domains rich in $A$ and $B$ become smoother and mixing between species increases. This leads to the decrease of difference in $T_{\mathrm{g}} \mathrm{s}$ of A-rich and B-rich areas of the melt and increase of corresponding breadths of glass transitions. Both $\mathbf{A}_{\mathbf{1 0}} \mathbf{B}_{\mathbf{1 0}}$ diblock copolymers (see below) and icosablock demonstrate one glass transition temperature indicating the presence large degree of homogeneity in theses samples compared to other multiblocks. However, the fact that the breadth of glass transition in both cases is larger than for random copolymer sample allows us to conclude that concentration fluctuations in Both $\mathbf{A}_{10} \mathbf{B}_{10}$ diblock and icosablock are stronger than in randomly mixed system.

Polymer blends of the two different homopolymers with the same DP were also investigated by DSC (Table S8, Figures S43-S47). Based on the DSC thermograms, all blends investigated displayed two different $T_{\mathrm{g}} \mathrm{s}$, even at DP 10. Compared to the corresponding pristine homopolymers (Figure 2, for the comparison to the multiblock copolymers, see Figure S48), most of the $T_{\mathrm{g}}$ values of the $\mathbf{A}$ component in the polymer blends were similar but a slight decrease in the $T_{\mathrm{g}}$ values of the $\mathbf{B}$ portion was observed in the polymer blends. Most notably, the B portion in the polymer blend of DP 10 showed a more pronounced decrease (from $13{ }^{\circ} \mathrm{C}$ for the homopolymer to $-2.5^{\circ} \mathrm{C}$ for the blend) compared to the polymer blends composed of longer homopolymer chains. This phenomenon can be explained by the fact that the fraction of $\mathbf{A}$ polymer inside the $\mathbf{B}$-rich phase and the fraction of $\mathbf{B}$ polymer inside the $\mathbf{A}$ rich phase increases upon decrease in chain length affecting the observed glass transition 
temperatures. In order to make a rough estimation of this effect we calculated concentrations of Arich and B-rich phases using the Flory-Huggins expression for the free energy of the mixture ${ }^{68,80}$ and then used the obtained concentration to predict shifts in glass transition temperatures using the Fox equation. ${ }^{69}$ Comparison of calculations with experimental data can be found in the ESI (Figure S49). Qualitatively, the dependence of glass transition temperatures of the homopolymer mixtures on their length is closely matched, however the reduction in the higher glass transition temperature of mixtures of longer homopolymers compared to pure polymer $\mathbf{B}$ is not yet fully aligned and requires the development of a more suitable theoretical model.

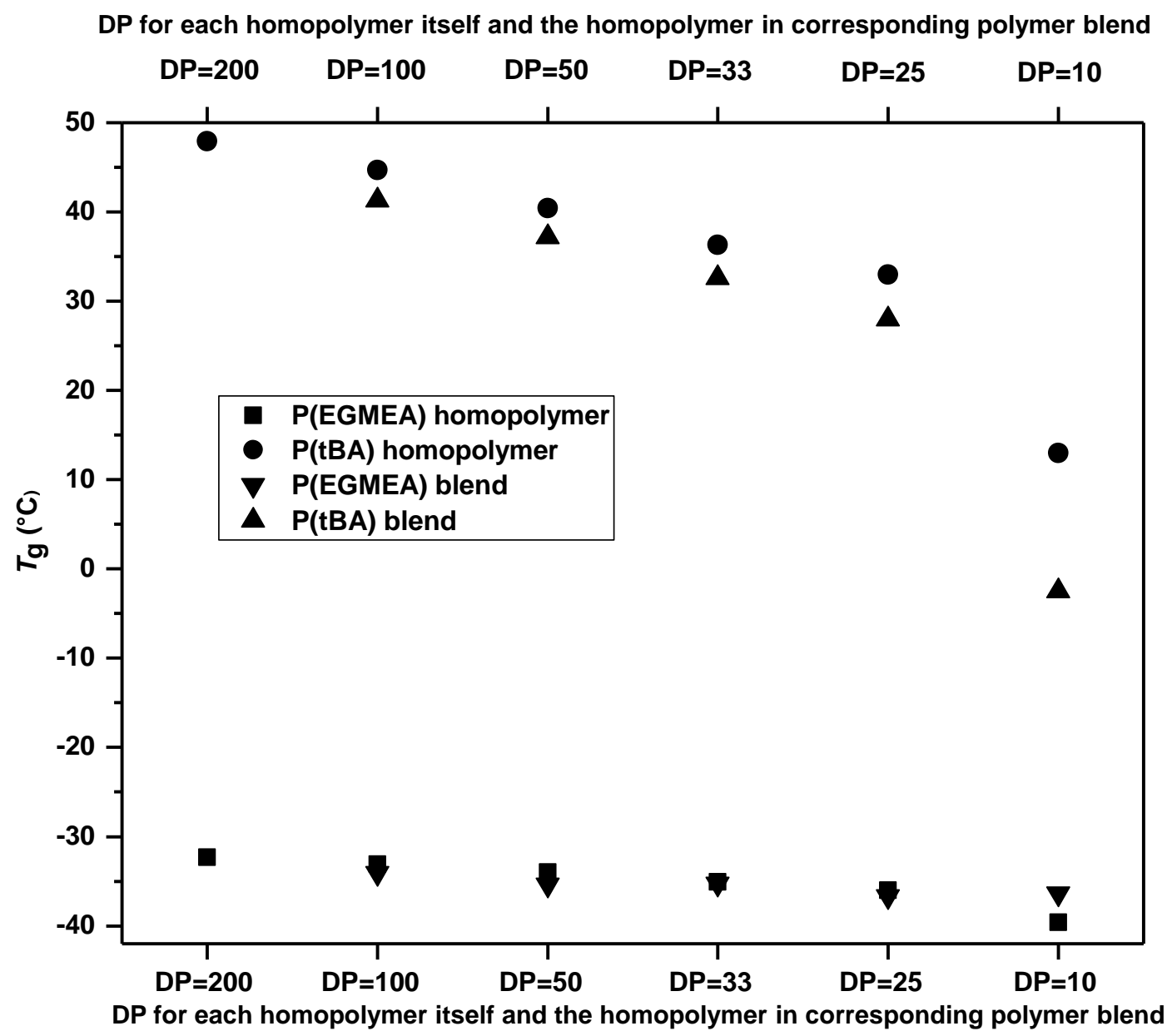

Figure 2. The comparison of $T_{\mathrm{g}}$ values of homopolymers ( $D P=200,100,50,33,25$ and 10) and corresponding polymer blends. Data represent mean values only (error bars within point size, see Tables 1 and $\mathbf{S 8}$ for SD).

In order to investigate the influence of the overall molecular weight on the phase separation, diblock copolymers with segment size matching those of the MBCPs (e.g. $\mathbf{A}_{10} \mathbf{B}_{10}$ corresponding to $\mathbf{B C P} \mathbf{P}^{\text {icosa }}$ and $\mathbf{A}_{25} \mathbf{B}_{25}$ corresponding to $\mathbf{B C}{ }^{\text {octa) }}$ ) were synthesized and analysed by DSC (Figures S11, S50-S53). Importantly, all diblock copolymers showed similar $T_{\mathrm{g}}$ values to the corresponding MBCPs (Table S8, 
Figure S54), which suggests similar molecular environments ${ }^{70}$ in agreement with overall similarities in the phase behaviour of diblock copolymers and $(A B)_{n}$ multiblock copolymers.

The microphase separation of the MBCPs with varying degrees of segmentation was also investigated using small angle $\mathrm{X}$-ray scattering (Figure $\mathbf{3}$ ).

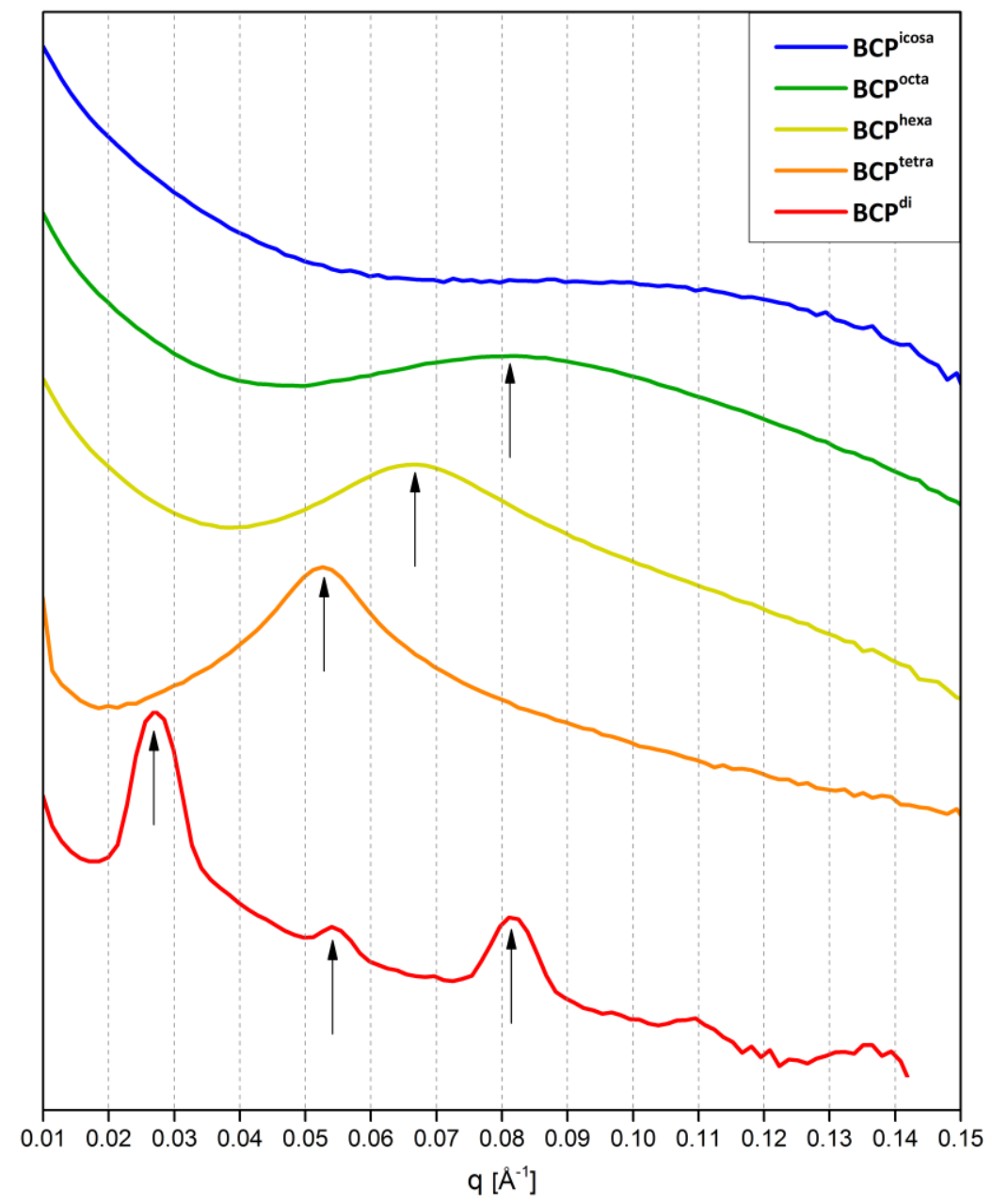

Figure 3: Radially integrated small angle X-ray scattering data for different MBCPs, the measurements were carried out at $-30^{\circ} \mathrm{C}$ for the $\mathbf{B C P}^{\text {hexa }}, \mathbf{B C P}^{\text {octa }}$, and $\mathbf{B C} \mathbf{P}^{\text {icosa }}$ - all measurements were performed for $2 \mathrm{~h}$. (y-axis in log scale, traces have been translated along the intensity axis for clarity purposes) As can be seen, three distinct reflexes can be observed for the diblock copolymer $\mathbf{A}_{100} \mathbf{B}_{100}$ with [100] : [200] : [300] $=0.027 \AA^{-1}: 0.054 \AA^{-1}: 0.081 \AA^{-1}$, indicative of a lamellar morphology in the bulk state, with an overall long period of $d=23 \mathrm{~nm}$ (calculated using the Bragg equation according to the reflection assigned as [100]; $d=2 \pi / q$, where $q$ is the scattering vector of the peak). Structure factors of all other samples demonstrate only one main peak indicating the absence of long-range order. The tetrablock, $\mathbf{A}_{50} \mathbf{B}_{50} \mathbf{A}_{50} \mathbf{B}_{50}$, shows one distinctly broader reflection at $q=0.052 \AA^{-1}$, which corresponds to a characteristic length scale of monomer density fluctuations of $12 \mathrm{~nm}$. This trend continues for the 
hexablock copolymer, where an even broader reflection at $q=0.068 \AA^{-1}$ is found, showing that the presence of compositional heterogeneity, albeit being far less pronounced $(d=9 \mathrm{~nm})$. It should be noted that for this sample, as for the octa- and icosablock copolymer, the measurement was carried out at $-30{ }^{\circ} \mathrm{C}$ to account for the rather oily consistency of the material at room temperature and, in addition, phase separation might be more pronounced at lower temperatures (due to the associated increase in the Flory-Huggins interaction parameter between the two blocks, $\left.\chi_{A-B}\right)$. In the case of the octablock copolymer, the observed reflection with a maximum in intensity at $q=0.081 \AA^{-1}$ increases further in width and shows that there is much less order in the system and the interfaces between the A-rich and B-rich domains are significantly less well-defined. The icosablock copolymer which has one glass transition temperature according to DSC measurements shows structure factor with extremely broad and weak peak. So it can be concluded that in this case a preferable wavelength of fluctuations in the system cannot be determined due to the high degree of homogeneity. Here it is worth to mention that as molecular weight distribution can significantly affect the phase behaviour of block copolymers, ${ }^{71-73}$ the high dispersity of the $\mathbf{B C P}^{\text {icosa }}(\theta=1.67)$ could also influence the phase separation and explain the presence of one single $T_{\mathrm{g}}$. However, considering the segment lengths are similar even with a high dispersity and the fact that the diblock copolymer $\mathbf{A}_{\mathbf{1 0}} \mathbf{B}_{10}$ has a low dispersity $(\theta=1.15)$ but also displays only one $T_{\mathrm{g}}$ (Table S8, Figures S53 and S54), it can be speculated that dispersity is not the main driving force to prevent phase separation for BCPicosa. Summarising we can conclude that all multiblock samples except diblock copolymer $\mathbf{A}_{100} \mathbf{B}_{100}$ are in a disordered state, however, as far as tetrablock, hexablock and octablock copolymers show two distinct glass transition temperatures these disordered states are microscopically inhomogeneous and may have liquid-like order with the domain size $d=2 \pi / q^{*}$ defined by the position of the peak $q^{*}$ of structure factor.

According to the mean-field theory dimensions of block copolymers in a disordered state must be Gaussian for flexible chains ${ }^{74}$ and correspondingly domain size should scale as $\mathrm{N}^{0.5}$ with number of segments in a chain. However, the plot of log $d$ versus log $\mathrm{N}_{\text {eff }}$ (Figure S56) for the multiblock copolymer series where $d=2 \pi / q^{*}$ and $N_{\text {eff }}$ is the total degree of polymerization of the diblock copolymer obtained by cutting the multiblock copolymer at even junctions between blocks (as shown in Figure S56b), gives an approximate linear correlation (regression value, $r^{2} \sim 0.98$ ) with an $\alpha$ value of 0.78 indicating non-Gaussian (more extended) conformation of the chains, which is in line with other reports on diblock copolymers. ${ }^{75-79}$

\section{Conclusion}

In summary, a series of sequence controlled multiblock copolymers using EGMEA and tBA were synthesized by RAFT polymerization and their microphase separation was studied by investigating the 
glass transition temperatures using DSC analysis. Compared to the homopolymers and homopolymer blends, the glass transition temperatures of the multiblock copolymers displayed a more distinct trend which evolves according to the number of segments. A counter trend behavior of the $T_{\mathrm{g}} \mathrm{s}$ of the polyEGMEA blocks was observed in the multiblock copolymers compared to the homopolymers with decreasing DP. Diblock copolymers composed of blocks of the same length as the segments of the multiblock copolymers displayed similar thermal characteristics to their corresponding multiblock copolymers. In addition, SAXS analyses showed that all multiblock copolymers except diblock copolymers (which show lamellae morphology) are in a disordered inhomogeneous state (up to and including octablock copolymers) with a characteristic size of inhomogeniety decreasing when lowering the size of the blocks with a dependence of $\mathrm{N}_{\text {eff }}{ }^{0.78}$, where $\mathrm{N}_{\text {eff }}$ is the total length of two of the polymer blocks. Our findings show that the glass transition temperatures of the multiblocks are akin to that of individual diblock copolymers of equivalent block lengths. This approach therefore can be used to modulate the $T_{\mathrm{g}}$ and domain sizes of a block copolymer by keeping the ratio of monomer and overall DP of each monomer constant, but varying the number of segments in the copolymer.

\section{Acknowledgements}

The Royal Society Wolfson Merit Award (WM130055; SP), and the Monash-Warwick Alliance is acknowledged for funding (SP; JZ, LM). MH gratefully acknowledges the German Research Foundation (DFG, GZ: HA 7725/1-1) for funding. F. H. S. and R. D. acknowledge support within the priority program on self-healing materials (SPP1568, SCHA1640/10-1) and by the Thuringian Ministry of Science, Education, and Culture (TMBWK; Grant No. B515-11028). JT is funded by Engineering and Physical Sciences Research Council (EPSRC) under grant EP/F500378/1 through the Molecular Organisation and Assembly in Cells Doctoral Training Centre (MOAC-DTC). P. D. T. and E. P. have received funding from the European Union Horizon2020 (H2020-MSCA-IF-2015 HYBOCOMIX no. 704459).

\section{References:}

1. Gody, G.; Maschmeyer, T.; Zetterlund, P. B.; Perrier, S. Rapid and quantitative one-pot synthesis of sequence-controlled polymers by radical polymerization. Nat. Commun. 2013, 4, 2505. 2. Lodge, T. P. Block Copolymers: Past Successes and Future Challenges. Macromol. Chem. Phys. 2003, 204, (2), 265-273.

3. Lutz, J.-F. Sequence-controlled polymerizations: the next Holy Grail in polymer science? Polym. Chem. 2010, 1, (1), 55.

4. Discher, D. E.; Eisenberg, A. Polymer Vesicles. Science 2002, 297, (5583), 967-973.

5. Harada, A.; Kataoka, K. Chain Length Recognition: Core-Shell Supramolecular Assembly from Oppositely Charged Block Copolymers. Science 1999, 283, (5398), 65-67.

6. Badi, N.; Lutz, J. F. Sequence control in polymer synthesis. Chem. Soc. Rev. 2009, 38, (12), 3383-90. 
7. Lutz, J.-F.; Ouchi, M.; Liu, D. R.; Sawamoto, M. Sequence-Controlled Polymers. Science 2013, 341, (6146), 628-636.

8. Gody, G.; Maschmeyer, T.; Zetterlund, P. B.; Perrier, S. Exploitation of the Degenerative Transfer Mechanism in RAFT Polymerization for Synthesis of Polymer of High Livingness at Full Monomer Conversion. Macromolecules 2014, 47, (2), 639-649.

9. Gody, G.; Maschmeyer, T.; Zetterlund, P. B.; Perrier, S. Pushing the Limit of the RAFT Process: Multiblock Copolymers by One-Pot Rapid Multiple Chain Extensions at Full Monomer Conversion. Macromolecules 2014, 47, (10), 3451-3460.

10. Pfeifer, S.; Lutz, J.-F. A Facile Procedure for Controlling Monomer Sequence Distribution in Radical Chain Polymerizations. J. Am. Chem. Soc. 2007, 129, (31), 9542-9543.

11. Zamfir, M.; Lutz, J.-F. Ultra-precise insertion of functional monomers in chain-growth polymerizations. Nat. Commun. 2012, 3, 1138.

12. Bita, I.; Yang, J. K. W.; Jung, Y. S.; Ross, C. A.; Thomas, E. L.; Berggren, K. K. Graphoepitaxy of Self-Assembled Block Copolymers on Two-Dimensional Periodic Patterned Templates. Science 2008, 321, (5891), 939-943.

13. Ruiz, R.; Kang, H.; Detcheverry, F. A.; Dobisz, E.; Kercher, D. S.; Albrecht, T. R.; de Pablo, J. J.; Nealey, P. F. Density Multiplication and Improved Lithography by Directed Block Copolymer Assembly. Science 2008, 321, (5891), 936-939.

14. Sun, J.; Teran, A. A.; Liao, X.; Balsara, N. P.; Zuckermann, R. N. Nanoscale Phase Separation in Sequence-Defined Peptoid Diblock Copolymers. J. Am. Chem. Soc. 2013, 135, (38), 14119-14124.

15. Mansky, P.; Liu, Y.; Huang, E.; Russell, T. P.; Hawker, C. Controlling Polymer-Surface Interactions with Random Copolymer Brushes. Science 1997, 275, (5305), 1458-1460.

16. Li, Z.; Kesselman, E.; Talmon, Y.; Hillmyer, M. A.; Lodge, T. P. Multicompartment Micelles from ABC Miktoarm Stars in Water. Science 2004, 306, (5693), 98-101.

17. Park, C.; Yoon, J.; Thomas, E. L. Enabling nanotechnology with self assembled block copolymer patterns. Polymer 2003, 44, (22), 6725-6760.

18. Sun, J.; Stone, G. M.; Balsara, N. P.; Zuckermann, R. N. Structure-Conductivity Relationship for Peptoid-Based PEO-Mimetic Polymer Electrolytes. Macromolecules 2012, 45, (12), 5151-5156.

19. Irwin, M. T.; Hickey, R. J.; Xie, S.; So, S.; Bates, F. S.; Lodge, T. P. Structure-Conductivity Relationships in Ordered and Disordered Salt-Doped Diblock Copolymer/Homopolymer Blends. Macromolecules 2016, 49, (18), 6928-6939.

20. Singh, M.; Odusanya, O.; Wilmes, G. M.; Eitouni, H. B.; Gomez, E. D.; Patel, A. J.; Chen, V. L.; Park, M. J.; Fragouli, P.; latrou, H.; Hadjichristidis, N.; Cookson, D.; Balsara, N. P. Effect of Molecular Weight on the Mechanical and Electrical Properties of Block Copolymer Electrolytes.

Macromolecules 2007, 40, (13), 4578-4585.

21. Förster, S.; Plantenberg, T. From Self-Organizing Polymers to Nanohybrid and Biomaterials. Angew. Chem. Int. Ed. 2002, 41, (5), 688-714.

22. Hamley, I. W. Nanotechnology with Soft Materials. Angew. Chem. Int. Ed. 2003, 42, (15), $1692-1712$.

23. Kubowicz, S.; Baussard, J.-F.; Lutz, J.-F.; Thünemann, A. F.; von Berlepsch, H.; Laschewsky, A. Multicompartment Micelles Formed by Self-Assembly of Linear ABC Triblock Copolymers in Aqueous Medium. Angew. Chem. Int. Ed. 2005, 44, (33), 5262-5265.

24. Stupp, S. I.; LeBonheur, V.; Walker, K.; Li, L. S.; Huggins, K. E.; Keser, M.; Amstutz, A. Supramolecular Materials: Self-Organized Nanostructures. Science 1997, 276, (5311), 384-389.

25. Matsen, M. W. Effect of Architecture on the Phase Behavior of AB-Type Block Copolymer Melts. Macromolecules 2012, 45, (4), 2161-2165.

26. Matsen, M. W.; Schick, M. Stable and Unstable Phases of a Linear Multiblock Copolymer Melt. Macromolecules 1994, 27, (24), 7157-7163.

27. Benoit, H.; Hadziioannou, G. Scattering theory and properties of block copolymers with various architectures in the homogeneous bulk state. Macromolecules 1988, 21, (5), 1449-1464. 
28. Kavassalis, T. A.; Whitmore, M. D. On the theory of linear multiblock copolymers. Macromolecules 1991, 24, (19), 5340-5345.

29. Zielinski, J. M.; Spontak, R. J. Confined single-chain model of microphase-separated multiblock copolymers. 1. (AB)n copolymers. Macromolecules 1992, 25, (2), 653-662.

30. Wu, L.; Cochran, E. W.; Lodge, T. P.; Bates, F. S. Consequences of Block Number on the Order-Disorder Transition and Viscoelastic Properties of Linear (AB)n Multiblock Copolymers. Macromolecules 2004, 37, (9), 3360-3368.

31. Rasmussen, K. Ø.; Kober, E. M.; Lookman, T.; Saxena, A. Morphology and bridging properties of (AB)n multiblock copolymers. J. Polym. Sci., Part B: Polym. Phys. 2003, 41, (1), 104-111.

32. Dobrynin, A. V.; Erukhimovich, I. Y. Computer-aided comparative investigation of architecture influence on block copolymer phase diagrams. Macromolecules 1993, 26, (2), 276-281.

33. Lee, I.; Panthani, T. R.; Bates, F. S. Sustainable Poly(lactide-b-butadiene) Multiblock Copolymers with Enhanced Mechanical Properties. Macromolecules 2013, 46, (18), 7387-7398.

34. Lee, I.; Bates, F. S. Synthesis, Structure, and Properties of Alternating and Random Poly(styrene-b-butadiene) Multiblock Copolymers. Macromolecules 2013, 46, (11), 4529-4539.

35. Panthani, T. R.; Bates, F. S. Crystallization and Mechanical Properties of Poly(I-lactide)-Based Rubbery/Semicrystalline Multiblock Copolymers. Macromolecules 2015, 48, (13), 4529-4540.

36. Martello, M. T.; Schneiderman, D. K.; Hillmyer, M. A. Synthesis and Melt Processing of Sustainable Poly( $\varepsilon$-decalactone)-block-Poly(lactide) Multiblock Thermoplastic Elastomers. ACS Sustainable Chemistry \& Engineering 2014, 2, (11), 2519-2526.

37. Spontak, R. J.; Smith, S. D. Perfectly-alternating linear (AB)n multiblock copolymers: Effect of molecular design on morphology and properties. J. Polym. Sci., Part B: Polym. Phys. 2001, 39, (9), 947-955.

38. Beck, K. R.; Korsmeyer, R.; Kunz, R. J. An overview of the glass transition temperature of synthetic polymers. J. Chem. Educ. 1984, 61, (8), 668.

39. Fulchiron, R.; Belyamani, I.; Otaigbe, J. U.; Bounor-Legaré, V. A simple method for tuning the glass transition process in inorganic phosphate glasses. Scientific Reports 2015, 5, 8369.

40. Behl, M.; Lendlein, A. Shape-memory polymers. Mater. Today 2007, 10, (4), 20-28.

41. Meng, H.; Li, G. A review of stimuli-responsive shape memory polymer composites. Polymer 2013, 54, (9), 2199-2221.

42. Huang, W. M.; Yang, B.; Zhao, Y.; Ding, Z. Thermo-moisture responsive polyurethane shapememory polymer and composites: a review. J. Mater. Chem. 2010, 20, (17), 3367-3381.

43. Wache, H. M.; Tartakowska, D. J.; Hentrich, A.; Wagner, M. H. Development of a polymer stent with shape memory effect as a drug delivery system. J. Mater. Sci. Mater. Med. 2003, 14, (2), 109-112.

44. Lendlein, A.; Langer, R. Biodegradable, Elastic Shape-Memory Polymers for Potential Biomedical Applications. Science 2002, 296, (5573), 1673-1676.

45. Metcalfe, A.; Desfaits, A.-C.; Salazkin, I.; Yahia, L. H.; Sokolowski, W. M.; Raymond, J. Cold hibernated elastic memory foams for endovascular interventions. Biomaterials 2003, 24, (3), 491497.

46. Tobushi, H.; Hara, H.; Yamada, E.; Hayashi, S. In Thermomechanical properties of shape memory polymer of polyurethane series and their applications, 1996; 1996; pp 418-423.

47. Boden, N.; Leng, S. A.; Ward, I. M. Ionic conductivity and diffusivity in polyethylene oxode/electrolyte solutions as models for polymer electrolytes. Solid State lonics 1991, 45, (3-4), 261-270.

48. White, R. P.; Lipson, J. E. G. Polymer Free Volume and Its Connection to the Glass Transition. Macromolecules 2016, 49, (11), 3987-4007.

49. Geng, K.; Tsui, O. K. C. Effects of Polymer Tacticity and Molecular Weight on the Glass Transition Temperature of Poly(methyl methacrylate) Films on Silica. Macromolecules 2016, 49, (7), 2671-2678. 
50. Walker, C. N.; Sarapas, J. M.; Kung, V.; Hall, A. L.; Tew, G. N. Multiblock Copolymers by Thiol Addition Across Norbornene. ACS Macro Letters 2014, 3, (5), 453-457.

51. Ellison, C. J.; Mundra, M. K.; Torkelson, J. M. Impacts of Polystyrene Molecular Weight and Modification to the Repeat Unit Structure on the Glass Transition-Nanoconfinement Effect and the Cooperativity Length Scale. Macromolecules 2005, 38, (5), 1767-1778.

52. Boukis, A. C.; Llevot, A.; Meier, M. A. R. High Glass Transition Temperature Renewable Polymers via Biginelli Multicomponent Polymerization. Macromol. Rapid Commun. 2016, 37, (7), 643-649.

53. Vanderlaan, M. E.; Hillmyer, M. A. "Uncontrolled” Preparation of Disperse Poly(lactide)block-poly(styrene)-block-poly(lactide) for Nanopatterning Applications. Macromolecules 2016, 49, (21), 8031-8040.

54. Shi, Y.; Cao, X.; Luo, S.; Wang, X.; Graff, R. W.; Hu, D.; Guo, R.; Gao, H. Investigate the Glass Transition Temperature of Hyperbranched Copolymers with Segmented Monomer Sequence. Macromolecules 2016, 49, (12), 4416-4422.

55. Zhong, M.; Matyjaszewski, K. How Fast Can a CRP Be Conducted with Preserved Chain End Functionality? Macromolecules 2011, 44, (8), 2668-2677.

56. Postma, A.; Davis, T. P.; Li, G.; Moad, G.; O'Shea, M. S. RAFT Polymerization with Phthalimidomethyl Trithiocarbonates or Xanthates. On the Origin of Bimodal Molecular Weight Distributions in Living Radical Polymerization. Macromolecules 2006, 39, (16), 5307-5318.

57. Moad, G.; Mayadunne, R. T. A.; Rizzardo, E.; Skidmore, M.; Thang, S. H., Kinetics and Mechanism of RAFT Polymerization. In Advances in Controlled/Living Radical Polymerization, American Chemical Society: 2003; Vol. 854, pp 520-535.

58. Moad, G.; Barner-Kowollik, C., The Mechanism and Kinetics of the RAFT Process: Overview, Rates, Stabilities, Side Reactions, Product Spectrum and Outstanding Challenges. In Handbook of RAFT Polymerization, Wiley-VCH Verlag GmbH \& Co. KGaA: 2008; pp 51-104.

59. He, R.; Kyu, T. Effect of Plasticization on Ionic Conductivity Enhancement in Relation to Glass Transition Temperature of Crosslinked Polymer Electrolyte Membranes. Macromolecules 2016, 49, (15), 5637-5648.

60. Fox, T. G.; Flory, P. J. The glass temperature and related properties of polystyrene. Influence of molecular weight. J. Polym. Sci. 1954, 14, (75), 315-319.

61. Fox, T. G.; Flory, P. J. Second-Order Transition Temperatures and Related Properties of Polystyrene. I. Influence of Molecular Weight. J. Appl. Phys. 1950, 21, (6), 581-591.

62. Zhang, L.; Marsiglio, J. A.; Lan, T.; Torkelson, J. M. Dramatic Tunability of the Glass Transition Temperature and Fragility of Low Molecular Weight Polystyrene by Initiator Fragments Located at Chain Ends. Macromolecules 2016, 49, (6), 2387-2398.

63. Hossain, M. D.; Lu, D.; Jia, Z.; Monteiro, M. J. Glass Transition Temperature of Cyclic Stars. ACS Macro Letters 2014, 3, (12), 1254-1257.

64. Rizos, A. K.; Ngai, K. L. Local Segmental Dynamics of Low Molecular Weight Polystyrene: New Results and Interpretation. Macromolecules 1998, 31, (18), 6217-6225.

65. Wooley, K. L.; Hawker, C. J.; Pochan, J. M.; Frechet, J. M. J. Physical properties of dendritic macromolecules: a study of glass transition temperature. Macromolecules 1993, 26, (7), 1514-1519. 66. Roland, C. M.; Nagi, K. L. Segmental Relaxation in Poly(dimethylsiloxane). Macromolecules 1996, 29, (17), 5747-5750.

67. Farrington, P. J.; Hawker, C. J.; Fréchet, J. M. J.; Mackay, M. E. The Melt Viscosity of Dendritic Poly(benzyl ether) Macromolecules. Macromolecules 1998, 31, (15), 5043-5050.

68. Flory, P. J. Thermodynamics of Heterogeneous Polymers and Their Solutions. The Journal of Chemical Physics 1944, 12, (11), 425-438.

69. Fox, T. G. Influence of diluent and of copolymer composition on the glass temperature of a polymer system. The Bulletin of the American Physical Society 1956, 1, 123-132.

70. Lodge, T. P.; McLeish, T. C. B. Self-Concentrations and Effective Glass Transition Temperatures in Polymer Blends. Macromolecules 2000, 33, (14), 5278-5284. 
71. Lynd, N. A.; Meuler, A. J.; Hillmyer, M. A. Polydispersity and block copolymer self-assembly. Prog. Polym. Sci. 2008, 33, (9), 875-893.

72. Lynd, N. A.; Hillmyer, M. A. Influence of Polydispersity on the Self-Assembly of Diblock Copolymers. Macromolecules 2005, 38, (21), 8803-8810.

73. Cooke, D. M.; Shi, A.-C. Effects of Polydispersity on Phase Behavior of Diblock Copolymers. Macromolecules 2006, 39, (19), 6661-6671.

74. Leibler, L. Theory of Microphase Separation in Block Copolymers. Macromolecules 1980, 13, (6), 1602-1617.

75. Kim, S.; Nealey, P. F.; Bates, F. S. Directed Assembly of Lamellae Forming Block Copolymer Thin Films near the Order-Disorder Transition. Nano Lett. 2014, 14, (1), 148-152.

76. Erothu, H.; Kolomanska, J.; Johnston, P.; Schumann, S.; Deribew, D.; Toolan, D. T. W.; Gregori, A.; Dagron-Lartigau, C.; Portale, G.; Bras, W.; Arnold, T.; Distler, A.; Hiorns, R. C.; MokarianTabari, P.; Collins, T. W.; Howse, J. R.; Topham, P. D. Synthesis, Thermal Processing, and Thin Film Morphology of Poly(3-hexylthiophene)-Poly(styrenesulfonate) Block Copolymers. Macromolecules 2015, 48, (7), 2107-2117.

77. Hashimoto, T.; Tsukahara, Y.; Kawai, H. Structure and Properties of Tapered Block Polymers of Styrene and Isoprene II. Dynamic Mechanical Responses and Their Structural Interpretations.

Polym. J. 1983, 15, (10), 699-711.

78. Hashimoto, T.; Shibayama, M.; Kawai, H. Domain-Boundary Structure of Styrene-Isoprene Block Copolymer Films Cast from Solution. 4. Molecular-Weight Dependence of Lamellar Microdomains. Macromolecules 1980, 13, (5), 1237-1247.

79. Matsushita, Y.; Mori, K.; Saguchi, R.; Nakao, Y.; Noda, I.; Nagasawa, M. Molecular weight dependence of lamellar domain spacing of diblock copolymers in bulk. Macromolecules 1990, 23, (19), 4313-4316.

80. In the Flory-Huggins calculation we used a reference volume equal to $v_{0}=116.5 \mathrm{~cm}^{3} / \mathrm{mol}$, which is the average molar volume of $A$ and $B$ polymers. Correspondingly, the effective chain lengths of the polymers changed to $\mathrm{N}_{\mathrm{A}, \text { eff }}=0.9 \mathrm{~N}_{\mathrm{A}}$ and $\mathrm{N}_{\mathrm{B}, \text { eff }}=1.1 \mathrm{~N}_{\mathrm{B}}$. We do not take into account the dependence of the Flory-Huggins interaction parameter $(\chi)$ and assume that it is a constant corresponding to some temperature above the upper glass transition temperature of the mixture. The Flory-Huggins parameter was used as an adjustable parameter. 